\title{
Unusual in Water Multicomponent Reaction of 3-Amino-5-methylpyrazole, Acetylacetone and Aldehyde
}

Irina G. Tkachenko a,b,c, Sergey A. Komykhova,b*, Vladimir I. Musatov ${ }^{a}$, Valentyn A. Chebanov ${ }^{\mathrm{a}, \mathrm{b}}$, Sergey M. Desenko a,b

a State Scientific Institution "Institute for Single Crystals" of National Academy of Sciences of Ukraine, Nauky Ave 60, Kharkiv 61072 Ukraine

${ }^{\mathrm{b}}$ V. N. Karazin Kharkiv National University, Svobody Sq. 4, Kharkiv 61022 Ukraine

${ }^{\mathrm{c}}$ Kharkiv Forensic Science Center, Ministry of Internal Affairs of Ukraine, Kovtuna str., 32,

Kharkiv 61036 Ukraine

sserg.ko@gmail.com

Keywords: multicomponent reactions, heterocycles, 3-aminopyrazole derivative, in water synthesis, microwave-assisted synthesis, ultrasonication.

Multicomponent reaction of 3-amino-5-methylpyrazole, aliphatic aldehyde (paraformaldehyde or acetaldehyde) and acetylacetone in water by conventional heating, microwave or ultrasound activation undergoes on molar amounts of reagents $2: 1: 2$, respectively, leads bis(2,5,7trimethylpyrazolo[1,5-a]pyrimidin-6-yl)-substituted methane or to corresponding 1,1-bis-substituted ethane.

\section{Introduction}

Use of multicomponent reactions to synthesize complicated heterocyclic compounds is a modern trend in organic chemistry allowing minimization of synthetic steps and increasing yield of target compound [1]. However, sometimes an attempt to use multicomponent approach can give unexpected results that are completely different from those obtained by more traditional multistep synthesis.

Azolopyrimidines having a nodal nitrogen are excellent objects for both, either multicomponent [2] or sequential synthesis [3]
(Scheme 1); both of them presume use of diverse aminoazoles 1 (3-amino-1,2,4-triazole [4], 3-aminopyrazole [5], 5-aminotetrazole [6] etc) as a heterocyclization component. It is worth to note, exactly the multicomponent approach is gaining distribution last time, however, here is the probability of selectivity loss due to realization of side processes in multicomponent system. 


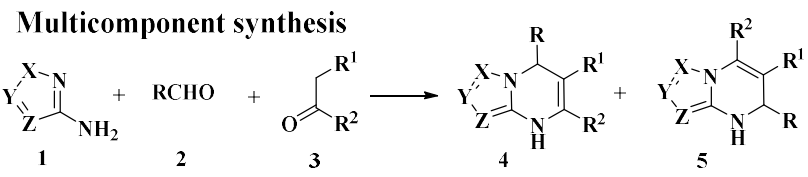

Sequential synthesis

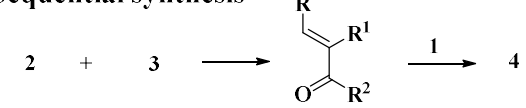

Scheme 1. Two approaches to synthesis of azolopyrimidines with a nodal nitrogen.

Another important trend in modern synthesis is "green chemistry" [7]; among its principles use of "green" solvents like water appeared to be highly effective [8].

In our recent publications $[9,10]$ we showed a possibility of obtaining azolopyrimidine in three-component way using 3-amino-1,2,4-triazole (6) and acetylacetone (8) as starting materials and water as solvent; the important feature of that research is use of formaldehyde (7a, [9]) or acetaldehyde (7b, [10]) as reagents (Scheme 2), whereas the majority of described data on azolopyrimidine synthesis presume use of exclusively aromatic aldehydes [3-6]. Application of aliphatic aldehydes allows to reduce molecular mass of target compounds and to satisfy the corresponding Lipinski criterion for biologically active compounds [11]. Typically, aminoazole with amidine moiety in multicomponent reaction with aldehyde and 1,3dicarbonyl compound reacts with formation of pyrimidine ring, therefore, such process undergoes in three-component way similar to well-known Biginelli reaction.

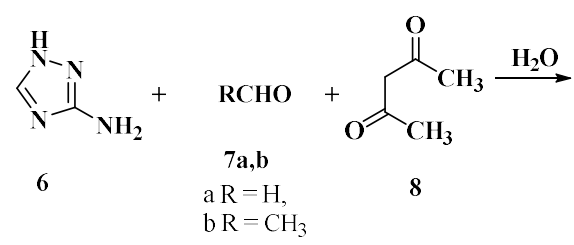<smiles>[R]C1C(C(C)=O)=C(C)Nc2ncnn21</smiles>

Scheme 2. Three-component in-water synthesis of 4,7dihydro-1,2,4-triazolo[1,5-a]pyrimidines $[9,10]$

In the current research, we attempted to extend the application of multicomponent approach and to synthesize pyrazolo[1,5a]pyrimidines using 3-aminopyrazole derivative and to check the scope and limitations of threecomponent in water synthesis concerning azolopyrimidines; however, our results here were somewhat unexpected.

\section{Results and discussion}

We studied the reaction of 3-amino-5methylpyrazole (10), aldehydes $\mathbf{7 a , b}$ and acetylacetone (8) in water and established the formation of single unusual product, namely bis(2,5,7-trimethylpyrazolo[1,5-a]pyrimidin-6yl)-methane (11a) or 1,1-bis(2,5,7trimethylpyrazolo[1,5-a]pyrimidin-6-yl)-ethane (11b), respectively (Scheme 3). Slight variation of the reaction conditions (using traditional heating as well as microwave or ultrasound activation) led to the same result: only compound 11 was isolated from the reaction mixture; the formation of "classical" dihydro derivatives like 12 was not observed even in trace. 
<smiles></smiles>

10

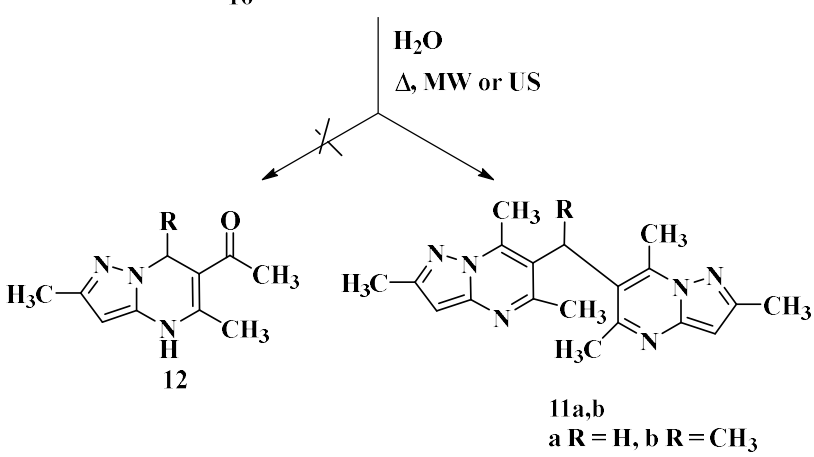

Scheme 3. In water reaction of 3-amino-5-methylpyrazole

(10) with aldehydes $7 \mathbf{a}, \mathbf{b}$ and acetylacetone $(\mathbf{8})$

Structures of 11a,b were confirmed by their spectral data: EI mass spectra of 11a,b showed molecule peaks that corresponded to participation of two molecules of $\mathbf{1 0}$ and $\mathbf{8}$ and only one molecule of $\mathbf{1}$ with loss of three molecules of water. ${ }^{1} \mathrm{H}$ NMR spectrum of 11a showed signals of three methyl groups (2.31, 2.44 and 2.53 ppm, each had intensity 6 protons) and signal of pyrazole proton at $6.63 \mathrm{ppm}$ (with intensity 2 protons) and signal of methylene group (4.00 ppm, two protons), which confirmed participation of compounds 10, 7 and 8 on molar amount 2:1:2, respectively, and allowed to propose structure 11a for the final product. Additionally, structures 11a,b were consistent with obtained ${ }^{13} \mathrm{C}$ NMR data.

Naturally, yields of 4 were low when equimolar amounts of 10, 7 and $\mathbf{8}$ were used for reaction; however, use of starting materials in stoichiometric amounts $(2: 1: 2)$ allowed to obtain reasonable yields for 11a, especially when microwave activation was applied; the best result (yield 65\%) was obtained by ultrasound activation (Table 1).

Table 1. Yields of 11a,b on different reaction conditions

\begin{tabular}{|c|c|c|c|}
\hline \multirow{2}{*}{ Compound } & \multicolumn{3}{|c|}{ Yield, \% $^{-}$} \\
\cline { 2 - 4 } & $\begin{array}{c}\text { Method } \\
\mathrm{A}^{\mathrm{a}}\end{array}$ & Method B $^{\mathrm{a}}$ & Method C $^{\mathrm{c}}$ \\
\hline 11a & 44 & 65 & 55 \\
\hline 11b & - & 40 & 35 \\
\hline
\end{tabular}

${ }^{\mathrm{a} C}$ Conventional heating, $30 \mathrm{~min}$

${ }^{b}$ Ultrasound activation, $25^{\circ} \mathrm{C}, 25-30 \mathrm{~min}$

${ }^{\mathrm{c}}$ Microwave activation, $25^{\circ} \mathrm{C}, 100 \mathrm{~min}$

It seems, mechanism of the current reaction (Scheme 4) should include at least the formation of key intermediate 14; the last one is formed evidently through the structure $\mathbf{1 3}$ which in turn is very likely responsible for possible formation of three-component product 12 (not observed in our case, however, is highly expectable in such kind of reactions $[9,10]$, Scheme 2). Realization of different reaction pathway can be explained by equilibrium process between adducts 13 and 14 in water in the presence of a base; difference in basicity of amine 10 (3-aminopyrazole derivative $\mathbf{1 0}$ has higher basicity, than amine 6 ) led to formation of unusual product, i. e. 11.

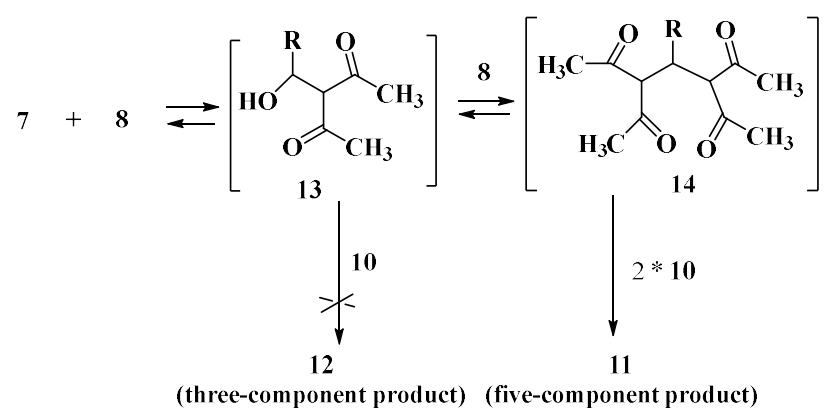

Scheme 4. Possible mechanism of formation of 11a,b. 
Microwave activation. A solution of

\section{Experimental part}

Material and methods. The melting points of all compounds synthesized were determined with a Gallenkamp melting point apparatus. The NMR spectra were recorded at $400 \mathrm{MHz}\left(100 \mathrm{MHz}\right.$ for $\left.{ }^{13} \mathrm{C}\right)$ with a Varian MR400 spectrometer. The EI MS spectra were measured on a GC-MS Varian 1200L (ionizing voltage $70 \mathrm{eV}$, direct input of the sample). Elemental analysis was realized on EuroVector EA-3000. Analytical samples of the compounds were obtained by their crystallization in water and further drying at room temperature. Microwave experiments were performed using the Emrys Creator EXP from Biotage AB (Uppsala, Sweden) possessing a single-mode microwave cavity producing controlled irradiation at $2.45 \mathrm{GHz}$. Sonication was carried out with help of standard ultrasonic bath producing irradiation at $44.2 \mathrm{kHz}$. Solvents, all reagents were commercially available and used without additional purification.

Synthesis. General procedure for synthesis of $11 a, b$.

Conventional heating. A solution of 3-amino-5-methylpyrazole (10, $2.4 \mathrm{mmol})$, aldehyde 7 (1.3 mmol; paraformaldehyde (7a) or acetaldehyde 7b) and acetylacetone (8, $2.4 \mathrm{mmol})$ in water $(5 \mathrm{~mL})$ was refluxed for 30 min. The crystalline product started to separate out during the reaction. The precipitate formed was filtered off, washed with water and air-dried. 3-amino-5-methylpyrazole (10, $2.4 \mathrm{mmol})$, aldehyde 7 (1.2 $\mathrm{mmol})$ and acetylacetone (8, $2.4 \mathrm{mmol})$ in water $(4 \mathrm{~mL})$ was irradiated in $\mathrm{MW}$ reactor at $100{ }^{\circ} \mathrm{C}$ for 100 minutes. The precipitate formed was filtered off, washed with water and air-dried.

Ultrasound activation. A solution of 3-amino-5-methylpyrazole (10, $2.4 \mathrm{mmol})$, aldehyde 7 (1.2 $\mathrm{mmol})$ and acetylacetone (8, $2.4 \mathrm{mmol})$ in water $(5 \mathrm{~mL})$ was continuously ultrasonicated at room temperature for 25-30 minutes. The crystalline product started to separate out either during the reaction. The precipitate formed was filtered off, washed with water and air-dried.

\section{bis(2,5,7-Trimethylpyrazolo[1,5-}

a]pyrimidin-6-yl)methane (11a). White solid, mp 215-217 ${ }^{\circ} \mathrm{C}$ (from ethanol). ${ }^{1} \mathrm{H} \quad \mathrm{NMR}$ (DMSO-d $\left.{ }_{6}\right): \delta 2.31\left(6 \mathrm{H}, \mathrm{s}, 2 \mathrm{CH}_{3}\right), 2.44(6 \mathrm{H}, \mathrm{s}, 2$ $\left.\mathrm{CH}_{3}\right), 2.53\left(6 \mathrm{H}, \mathrm{s}, 2 \mathrm{CH}_{3}\right), 4.00\left(2 \mathrm{H}, \mathrm{s}, \mathrm{CH}_{2}\right), 6.63$ (2H, s, 2 H-Pyrazol). ${ }^{13} \mathrm{C}$ NMR (DMSO-d 6 ): 13.3 $\left(2 \mathrm{CH}_{3}\right), 15.5\left(2 \mathrm{CH}_{3}\right), 16.7\left(2 \mathrm{CH}_{3}\right), 24.7\left(\mathrm{CH}_{2}\right)$, 105.9 (C-3, C-3'), 107.6 (C-6, C-6'), 144.6 (C-7, C-7'), 146.2 (C-3a, C-3a'), 152.4 (C-2, C-2'), 157.1 (C-5, C-5'). MS (EI, 70 eV): m/z (\%) 334 (33) $\left[\mathrm{M}^{+}\right], 173$ (23), 174 (99), 175 (13). Anal. Calcd for $\mathrm{C}_{19} \mathrm{H}_{22} \mathrm{~N}_{6}$ (334.19): C, 68.24; H, 6.63; N, $25.13 \%$. Found: C, 68.26; H, 6.66; N, 25.16\% 6,6'-(Ethane-1,1-diyl)bis(2,5,7trimethylpyrazolo $[1,5-a]$ pyrimidine) (11b). White solid, mp $148-150^{\circ} \mathrm{C}$ (from ethanol). ${ }^{1} \mathrm{H}$ NMR (400 MHz, DMSO-d 6$): \delta 1.90\left(3 \mathrm{H}, \mathrm{d},{ }^{3} \mathrm{~J}=\right.$ 
$\left.7.2 \mathrm{~Hz}, \mathrm{CH}_{3}\right), 2.36\left(6 \mathrm{H}, \mathrm{s}, 2 \mathrm{CH}_{3}\right), 2.45(6 \mathrm{H}, \mathrm{s}, 2$ $\left.\mathrm{CH}_{3}\right), 2.53\left(6 \mathrm{H}, \mathrm{s}, 2 \mathrm{CH}_{3}\right), 4.75\left(1 \mathrm{H}, \mathrm{q},{ }^{3} \mathrm{~J}=7.6\right.$ $\mathrm{Hz}), 6.62(2 \mathrm{H}, \mathrm{s}) .{ }^{13} \mathrm{C}$ NMR (DMSO-d $): 13.6$ (2 $\left.\mathrm{CH}_{3}\right), 15.8\left(2 \mathrm{CH}_{3}\right), 16.7\left(2 \mathrm{CH}_{3}\right), 21.8\left(\mathrm{CH}_{3}\right)$, $22.7(\mathrm{CH}), 104.5$ (C-3, C-3'), 106.8 (C-6, C-6'), 143.8 (C-7, C-7'), 146.1 (C-3a, C-3a'), 152.4 (C2, C-2'), 156.4 (C-5, C-5'). MS (EI, $70 \mathrm{eV}): \mathrm{m} / \mathrm{z}$

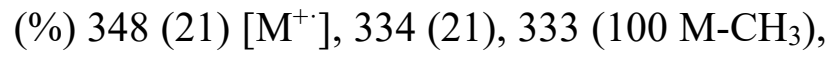
188 (27), 187 (20), 174 (11). Anal. Calcd for $\mathrm{C}_{20} \mathrm{H}_{24} \mathrm{~N}_{6}$ (348.21): C, 68.94; $\mathrm{H}, 6.94 ; \mathrm{N}$, 24.12\%. Found: C, 68.96; H, 6.98; N, 24.14\%.

\section{Conclusions}

Multicomponent reactions of 3-amino-5methylpyrazole with aliphatic aldehydes (formaldehyde, acetaldehyde) and acetylacetone in water undergo in five-component way with formation of bis-(6,6'-pyrazolo[1,5a]pyrimidine-substituted methane and 1,1-bis(6,6'-pyrazolo[1,5-a]pyrimidine-substituted ethane derivatives.

\section{Acknowledgements}

Authors thank National Academy of Sciences of Ukraine for financial support in the frame of the projects "Creation of modern bases for obtaining and analyzing substances and components of materials for pharmaceutical purposes" (0119U100727) and "Investigation of structural features of nitrogen containing heterocycles with potential biological activity" (0119U100716) and to Ministry of Education and Science of Ukraine for financial support in the frame of project "Molecular docking for express identification of new potential drugs" (0119U002550).

\section{References}

[1] Zhu J, Bienayme H. Multicomponent Reactions. Wiley-VCH: 2005; 484 p.

[2] Wermann K, Hartmann M. Synthesis of Dihydro-1,2,4-triazolo[1,5-a]pyrimidines. Synthesis 1991; (03): 189-191.

[3] Chebanov VA, Desenko SM, Gurley TW, Azaheterocycles Based on $\alpha, \beta$-Unsaturated Carbonyls. Springer; 2008, 212 p.

[4] Rudenko RV, Komykhov SA, Musatov VI, Desenko SM. New dihydro-1,2,4triazolo[1,5- $a]$ pyrimidines based on arylidene derivatives of 5-acetylbarbituric and dehydroacetic acids. J. Heterocyclic Chem. 2009, 46(2): 285-288.

[5] Kolosov MA, Beloborodov DA, Orlov VD, Dotsenko VV. Catalyst-free Biginelli-type synthesis of new functionalized 4,7-dihydropyrazolo[1,5a]pyrimidines. New J. Chem. 2016; 40(nb. 9):7573-7579.

[6] Kour P, Singh VP, Khajuria B, Singh T, Kumar A. Al(III) chloride catalyzed multi-component domino strategy: Synthesis of library of dihydrotetrazolo[1,5-a]pyrimidines and tetrahydrotetrazolo[1,5-a]quinazolinones. Tetrahedron Lett. 2017, 58: 4179-4185.

[7] Lancaster M. Green Chemistry: An Introductory Text. Cambridge: RSC; 2002, p 5.

[8] Grieco PA. Organic Synthesis in Water. Springer; 1998, p 302.

[9] Komykhov SA, Tkachenko IG, Musatov VI, Diachkov MV, Chebanov VA, Desenko SM. Multicomponent synthesis in water of 7-unsubstituted 4,7dihydro-1,2,4-triazolo[1,5-a]pyrimidines and their antimicrobial and antifungal activity. Arkivoc 2016; (iv): 277-287.

[10] Tkachenko IG, Komykhov SA, Gladkov ES, Musatov VI, Chebanov VA, Desenko SM. Acetic aldehyde in multicomponent synthesis of azolopyrimidine derivatives in water. Chem. Heterocycl. 
Compd. 2019; 55 (4/5): 392-396 [Khim. Geterotsikl.

Soedin. 2019; 55 (4/5): 392-396].

[11] Leeson P. Chemical beauty contest.

Nature 2012: 481: 455-456. 